\title{
IDENTIDADE E DIFERENÇA EM MOVIMENTO: \\ RESSONÂNCIAS DA OBRA DE DELEUZE
}

Marisa Lopes da Rocha ${ }^{\star}$

\begin{abstract}
RESUMO
O artigo pretende colocar em análise a lógica identitária que está na origem do Estado moderno, através de conceitos relativos à tese de reversão do platonismo. A perspectiva é a de retomar a obra deleuzeana, assim como a de diferentes autores que contribuem para seu entendimento como Machado, Orlandi, Fuganti, entre outros, evidenciando o insuportável da cultura ocidental-cristã: a ausência da identidade. Pensar em alternativas para a vida como potência de transformação implica dar visibilidade à lógica atravessada nas práticas, redimensionando o cotidiano como campo de forças que desconstroem os modelos a favor da afirmação da diferença.
\end{abstract}

Palavras-chave: Filosofia da diferença. Pensamento pós-moderno. Multiplicidade e Devir.

\section{IDENTITY AND DIFFERENCE IN MOVEMENT: REPERCUSSIONS OF DELEUZE'S WORKS}

\begin{abstract}
This paper intends to analysis the logic of identity which is in the origin of modernity, by means of concepts regarding to the reversion of platonism. We will be based on Deleuze's work, as well as on different authors like Machado, Orlandi and Fuganti, who help us to understand the contributions of Deleuze, putting forward an unbearable feature of occidental culture: the lack of identity. Thinking of alternatives for contemporary life as potency of changing requires giving visibility to the logic which supports the practices, putting forward the quotidian as a field of forces which break down the established models in behalf of affirming difference.
\end{abstract}

Keywords: Philosophy of difference. Thinking postmodern. Multiplicity and to become.

\footnotetext{
^ Professora do Programa de Pós-Graduação em Psicologia Social da Universidade do Estado do Rio de Janeiro, doutorado em Psicologia pela Pontifícia Universidade Católica de São Paulo e Bolsista do CNPq em pós-doutoramento na UNICAMP. Endereço: Rua Mário Coimbra Bouças, 10, Bl II, apt 501, Freguesia, Rio de Janeiro, RJ CEP 22743-675.

E-mail: rochadm@uol.com.brou marrocha@uerj.br
} 
Então, o artista é quase que um pecador, porque ele se mistura com Deus e quer, da mesma forma que Deus, criar novos mundos. E se não houvesse esses artistas criando novos mundos, Deus, que só fez um, nos obrigaria a viver nesse já insuportável (há séculos insuportável). E se não fossem os artistas, nós não teríamos o nascimento de sempre novos mundos.

Cláudio Ulpiano - A estética Deleuziana

Oficina Três Rios, PUC/SP (22/11/93).

\section{Construindo um Percurso}

Discutir o paradigma da modernidade que traça a produção do homem e do mundo em função de um futuro pré-determinado, de uma ordem universal e transcendente, é colocar em questão as marcas das relações entre a razão ocidental e a consciência religiosa. As tradições preservadas no mundo ocidental entrelaçam religião, filosofia e ciência, na perspectiva de um equilíbrio estabilizador de micropolíticas que agenciem transformações nos modos de subjetivação e, conseqüentemente, na própria história. Isto é o que buscaremos evidenciar a seguir, partindo de reflexões sobre conceitos que vão se constituir em territórios de passagem de uma etapa histórica a outra na luta por aprisionar/libertar a diferença que faz escapar a vida onde ela quer se fazer. Nosso percurso vai no rastro da lógica instituinte da cultura ocidental-cristã, em que o insuportável é a ausência da identidade, assim como das resistências que caminham no sentido de um devir outro, fortalecendo micropolíticas do desejo no eterno retorno à diferença. Para isso, diversos autores atravessados pela obra deleuzeana serão nossos aliados, resgatando uma filosofia maldita que ganha centralidade no pensamento de Nietzsche.

\section{UM RESGATE HISTÓRICO-FILOSÓFICO}

A perspectiva totalitária do mundo que inscreve a expectativa de harmonia está presente na consciência mítica de onde se desprende gradativamente a consciência filosófica. A filosofia que serviu de eixo para o desenvolvimento da ontologia no mundo ocidental, traz como problema a busca da restauração do equilíbrio vinculado ao universo mítico. Deste modo, os mitos estão vivos em novos ritos, e nossa civilização traz um tempo em que o passado e o futuro se organizam num contínuo, através da utopia de um velho/novo mundo. As diversas ciências e, no que nos concerne em especial, as ciências humanas, na medida em que vão ganhando corpo através da estruturação dos conhecimentos, contribuem para o processo que consolida as tradições da cultura ocidental-cristã. O mito dará lugar à história no ocidente, e a filosofia e o desenvolvimento científico contribuirão para produzir e pensar novas formas de relação homem/mundo. A razão ocidental, traduzida no comportamento científico, buscará uma verdade objetiva, intemporal e absoluta, cuja base está na possibilidade de comprovação, mas que se inscreve dentro de um sistema previamente considerado. O mito como funda- 
ção do temporal no intemporal se constitui como um princípio de inteligibilidade, satisfazendo a uma verdade antecedente como valor. A consciência mítica opera pelo princípio da conservação, conduzindo a experiência possível a um fenômeno conhecido, e funciona como um sistema analisador, pois conhece tensões, mas é essencialmente consciência da unidade.

A idéia de "universal" representa a integração de todos os elementos, dos mundos, das características dos homens. A vida é tomada numa dimensão geral, ampla, onde o não-similar, o não-assimilável, constitui uma ameaça ao equilíbrio estabelecido, sendo considerado um inimigo da ordem. A perspectiva da universalidade e da individualidade se destaca da consciência mítica, na qual a solidariedade dos homens é mantida através da autoridade transcendental. Gradativamente, o que ganha consistência é a arbitragem da razão, que supõe uma noção de "sujeito" como elemento de uma espécie, de uma comunidade, enfim, de um grupo cuja solidariedade é garantida pela mediação do social. O mundo sem expansão é tecido na idéia de sujeito que se integra no universo da existência em comum.

A revolução socrática e a tradição da filosofia do ocidente constituem a tradução da idéia universal na noção de lei. $\mathrm{O}$ embrião das formas político-sociais que ganham consistência na sociedade grega já está presente no desafio de manutenção dos grandes impérios como os do Egito e da Mesopotâmia, que se consolidaram, a partir de 3.000 a.C., na luta por apagar as diferenças locais. Assim, nossa civilização tem longa vida de transformações e de sagrados que constituíram maneiras repetidas, mecanismos semelhantes postos em marcha para responder aos desafios das mudanças históricas.

A sociedade que se estrutura técnica, política e socialmente alarga o sentido de mundo através da estratificação em classes diferentes pela divisão do processo de trabalho, da especialização de funções, das noções de direito e deveres e da submissão ao soberano. A ordem no novo regime requer a diversidade no interior da unidade, garantindo o comportamento solidário da massa.

A administração centralizada dos impérios demandará a constituição de estruturas e categorias para a coordenação política e social da vida pública. $\mathrm{O}$ surgimento de múltiplas junções e controle vai caracterizar as técnicas de governo como razão objetivada nas práticas policiais, judiciárias, econômicas, por meio de impostos. A estratificação do poder vai produzir longas cadeias de representação, onde a articulação com o real, com a experiência vivida, será cada vez mais mediada.

O conjunto das representações, valores e crenças na nova era intelectual e espiritual reorganiza as aparências e as ligações frágeis anteriormente estruturadas pela convocação participativa e pela idéia de pertencimento. A sistematização e a regulamentação inteligíveis e impessoais se apresentam sob a forma de lei que constitui o controle da realidade pela reflexão: a razão aparece como a capacidade de transcendência e recomposição do universo, mas também da vida do homem em sociedade. A ciência moderna trará consigo a busca de controle e comprovação da unidade do cosmos, da possibilidade de total inteligibilidade e do conhecimento da verdade através do estudo das regularidades. Tais princípios, que atra- 
vessam a filosofia grega, a filosofia romana e o cristianismo, enquanto organização da vida espiritual no ocidente, vigoram ainda hoje, quando o homem se curva frente ao movimento do mundo, buscando suas forças transcendentes. A lei intervém como realidade transcendental. O homem toma, deste modo, consciência da universalidade que no seu limite afirma a solidariedade e implica a compreensão do real como realidade total, plena e fechada em si mesma. A idéia de uma lei moral, impessoal, que marcará o destino do homem, será formulada por Sócrates e reafirmada na trajetória filosófico-religiosa que compõe o curso de nossa civilização.

O desmantelamento da unidade do poder mítico que assegurava ordem e harmonia social nos grandes impérios arcaicos não é realizado por Sócrates, pois o mundo mágico-religioso já estava em plena decomposição quando sua obra enuncia uma nova proposta de "mundo", de "homem" e de "sociedade". Na verdade, Sócrates, ganha importância frente aos pensadores de sua época porque, em lugar da aceitação natural das representações coletivas que subjugavam o ser ou de sua crítica, propõe a afirmação do homem que reflete. Na Grécia clássica, o homem substituirá a autoridade exterior das tradições pela autoridade que se afirma nele ou a partir dele. Assim, podemos pensar que, no mundo de Sócrates, ocorre uma transferência de poder. A personalidade refletida passa a constituir o centro do universo, onde generalidade e personalidade se fundam mutuamente. Na perspectiva de Gusdorf, a vinculação da autonomia da consciência como base de toda a normativa social aprisiona o ser, pois a verdade passa do regime do contrato coletivo para o do engajamento pessoal:

A determinação dos conceitos segundo a técnica dos diálogos socráticos remete o interlocutor a uma autoridade, ao mais profundo dele, que decide soberanamente sobre o falso e o verdadeiro. A verdade se pronuncia no indivíduo e não mais na comunidade. A pessoa torna-se fundamento, porque "é através de nós sozinhos que conheceremos a autenticidade de cada coisa" (Phédon 67a). A dialética é aqui interior ao pensamento. A consciência coletiva é o senso comum instalado em cada um, o domínio das evidências passivas e habituais, perseguida e reduzida por uma outra consciência, o bom senso da razão crítica, do qual cada homem tem sua parte e que a maiêutica de Sócrates libera (GUSDORF, 1984, p. 186).

Para Gusdorf, Sócrates é menos adversário das representações coletivas que fundador da razão. A nova civilização que se anuncia traz a norma inteligível, a reciprocidade do individual e do universal da humanidade, consagrando o acontecimento da razão à soberania. $\mathrm{O}$ homem descobre sua capacidade independente das referências transcendentes do mito, mas passa à interioridade da consciência de si, compreendida como uma referência transcendental.

Os precursores da filosofia ocidental são considerados por Fuganti (1990) como funcionários do Estado dito democrático e civilizado que surge na Grécia no século VI aC. Sócrates, Platão e Aristóteles preconizaram o pensamento como julgador da vida, sendo necessário o distanciamento desta para que a verdade seja 
atingida. O pensamento puro tem o corpo e suas intensidades como bloqueio. Para o autor, a aproximação entre mito e pensamento racional é à base da composição da sociedade grega. As leis, a moral e a razão constituídas a partir de Sócrates e Platão trazem o mundo religioso e violento da sociedade micênica, que está na origem da formação social do novo Estado. Assim, as forças do passado são trazidas pela repetição do mito que interage com os desafios do presente. O mito é o fundamento da filosofia platônica e constrói as bases epistemológica e metafísica do modo de pensar do ocidente e da razão da ciência moderna.

A divisão e a relação processada no mundo platônico se dá em função da verdade. $\mathrm{O}$ amor verdadeiro favorece o reconhecimento das idéias puras. A condição de acesso à verdade depende da natureza do amor, o que implica práticas de virtude e práticas de domínio de si. Deste modo, o verdadeiro amante é um sujeito da moral. O pensar não se constitui como produção do novo, mas como reconhecimento, sendo o valor de verdade conferido à capacidade de imitação. Conhecer está longe da processualidade, pois opera por recognição de uma idéia eterna e acabada (KASTRUP, 1999). O sujeito do conhecimento é o que estabelece semelhanças.

A narrativa mítica dos dois mundos em Platão permite a separação entre as idéias puras e impuras através dos princípios da identidade e semelhança. É a semelhança entre as imagens do mundo sensível e as idéias eternas que funda uma dialética não da competição, mas da rivalidade das formas. A hierarquia institui-se a partir do valor dos seres, definido pelo grau de semelhança entre a matéria efêmera e a idéia eterna. Para Deleuze (1974), mito e dialética, antes de serem excludentes, são complementares e fornecem a base necessária ao método da divisão platônico. Assim, na filosofia de Platão, o mundo e os corpos são desqualificados como potencialmente caóticos, e a vida, como natureza reativa; o pensar é fundado no negativo e reduzido à razão. Fuganti ressalta que a ordem do uno, do Bem, definida pela lógica identitária e pelo encadeamento causal, traz como implicação o conceito de simulacro - imagem sem semelhança, onde o desejo se perverteu como desejo de outras imagens distintas das estabelecidas como verdadeiras, pertencentes ao mundo divino:

A tautologia das proposições encerradas na identidade da Idéia gerou o problema das atribuições resolvido por Platão no Sofista, com a introdução do princípio de alteridade, o grande gênero do Outro, e que, como acreditamos, inaugura o pensamento por analogia, dispositivo sutil de depreciação da vida e negação da potência ontológica do pensamento (FUGANTI, 1990, p. 33).

Nesta perspectiva, a inserção do singular se faz por analogia ou afinidade. É ainda a máquina capitalística do mundo moderno que, na fala de Guattari (1986), trabalha, tradutibilizando as equivalências na produção da homogênese. $\mathrm{O}$ homem da virtude que veio se constituindo é o legislador esclarecido encarnado em forma de lei, é o prudente e saudável que cumpre os desígnios da razão. A cultura da moral iniciada na Grécia clássica tem o pensamento como dualista, essencialista e racionalista e, por seu caráter absoluto, traz como modelo de desenvolvimento a 
dinâmica evolutiva que, através da razão causalista, linear e homogênea, conserva mecanismos integradores do devir. A filosofia de Aristóteles trará, sem dúvida, novos dispositivos que, ligados aos anteriores, nos permitirão avançar na compreensão das idéias e valores priorizados em nossa civilização.

Em Aristóteles, o Bem é alcançado pelo homem virtuoso na conquista da ciência universal. Moral e ciência são aliados no estabelecimento da verdade. $\mathrm{O}$ senso comum é caracterizado pela multiplicidade de sentidos que, através da linguagem, meio de expressão da razão, pode atingir o bom senso que constitui a univocidade - um mesmo nome é atribuído a diversos sujeitos em um sentido semelhante. A linguagem em Aristóteles é um instrumento de purificação, de busca da coerência lógica, que leva a neutralidade à equivocidade - um mesmo nome é atribuído a vários sujeitos em um sentido totalmente diferente. O sujeito da moral utiliza seu potencial lógico para classificar e codificar as impurezas do múltiplo, atuando como um redutor das diferenças acidentais à identidade do gênero, e traduz em ato a unidade universal da razão. Assim, Aristóteles tira as idéias das alturas de um outro mundo e as encarna na alma humana, fundando a Psicologia e a compreensão do homem na dualidade da matéria sensível e da razão. A divisão enquanto método torna-se um procedimento de especificação. Para Deleuze (1988), Aristóteles inscreve a diferença em um conceito geral, o que significa mediatizála, representá-la. Deste modo, o registro da diferença se faz na identidade de um conceito indeterminado. É Aristóteles quem funda a lógica da representação, estabelecendo-a através da divisão em gênero e espécie.

Em Machado (1990) sobre a obra filosófica de Deleuze, encontramos a comparação entre os métodos de divisão para Platão e Aristóteles. Em Platão, a cópia está ligada por semelhança à idéia de algo. O modelo é a idéia, e a cópia se funda a partir de uma semelhança interna com a identidade da idéia vinculada ao mundo das alturas. Segundo Deleuze (1974), a motivação existente no processo platônico que cria a representação é a exclusão das cópias sem semelhança. A realidade advém de uma reconstituição feita pela razão. Neste método, as eliminações são produzidas pelas comparações consecutivas que classificam a boa e a má cópia. O que se efetua a partir da divisão de Platão é a autenticidade da idéia, e não as características da espécie, a identificação ou especificação do conceito, como no método da divisão aristotélica.

Machado ressalta ainda que a vontade platônica é a de expulsar os fantasmas e que, em Deleuze, o essencial não é a promoção de uma reversão do platonismo, virando o simulacro contra o modelo:

[...] o fundamental de sua estratégia antiplatônica de glorificação dos simula - cros é o projeto de abolir as noções de original e derivado, de modelo e de cópia, e a relação de semelhança estabelecida entre esses termos na medida em que tal tipo de pensamento reduz necessariamente a diferença à identidade (MACHADO, 1990, p. 34). 
Deleuze (1988) não tem como perspectiva básica a discussão da divisão entre natureza inteligível e sensível; antes, seu projeto filosófico visa ao fato de esta diferença ser subordinada à questão da representação, o que significa dar ênfase à identidade.

O caminho que percorremos até o momento corresponde à afirmação de nossa cultura que, através de São Tomás de Aquino, Descartes, Leibniz e tantos outros filósofos, preservou valores, por repetição no tempo, que acabaram se tornando princípios sagrados da civilização ocidental. O que queremos demonstrar é que o insuportável, nesta perspectiva, é a ausência de identidade. A importância de Deleuze para Orlandi (1989) está em evidenciar que a organização deste trajeto não se dá de forma pacífica, como se fôssemos espectadores e atores no desenrolar natural de uma história dos homens. A obra deleuzeana busca, antes, retomar práticas filosóficas que produziram outras formas de viver e de pensar a vida, no que esta tem de múltiplo (ZOURABICHVILI, 1994).

As duas grandes linhas de pensamento que se estruturam na cultura grega nos séculos V e IV a.C. apresentam-se polarizadas e constituem as vertentes da razão sedentária e do pensamento nômade. A primeira representa a ordem totalizadora das cidades-Estado, que anuncia a moral de cada indivíduo e do seu coletivo e os códigos sobre os quais a família se organizará como célula do Estado, sendo sua base a corrente socrática. A segunda advém dos pensadores présocráticos - sofistas, megários, cínicos e, posteriormente, estóicos e epicuristas, que preconizam a natureza como união dos elementos, do corpo e do pensamento, vendo a natureza e todo o sobrenatural, os deuses, como uma só coisa. O pensamento nômade constitui a busca de outros modos de ser e de perceber o mundo, e sua base está nas forças singulares da vida e do pensamento. Para estes pensadores, a vida não tem como princípio essencial a conservação ou as leis, mas a potência criadora e os riscos que ela implica. A idéia de um pensamento fruto de um corpo vivo e ativo e de uma ação advindo do pensamento afirmativo choca-se diretamente com a perspectiva socrática, segundo a qual, para bem julgar a vida e encontrar a verdade, deve o pensamento distanciar-se do mundo sensível e do próprio corpo (MENGUE, 1994).

A natureza pensada como multiplicidade, livre dos hábitos e normas humanas, é o que Fuganti ressalta da nova perspectiva, onde o homem é visto como natureza vinculada à profundidade dos elementos, e não mais às ordens trancendentes:

Se a orientação pré-socrática recai sobre a profundidade dos elementos da physis, guardando ainda certa unidade, os sofistas e os cínicos fazem explodir a multiplicidade dos pontos de vista. Não há para eles verdade absoluta. Tudo emerge e se institui segundo a diversidade das perspectivas e a mutação dos referenciais (FUGANTI, 1990, p. 46).

Assim, Fuganti estabelece que esta forma de pensamento privilegia as relações, desmanchando os códigos fixos e os valores que mantêm a separação dos seres e das alturas. 
Com os estóicos, as idéias universais e os modelos genéricos que estabelecem a identidade em relação à espécie perdem consistência ante a singularidade da potência dos corpos. A potência é o que define a essência de um corpo e esta é única, ou seja, não genérica ou específica, mas diferente de todas as outras e mesmo de si própria, na medida em que se transforma no tempo. Para os estóicos, não há natureza moral, pois negam a existência de leis gerais, cujos valores transcendentes servem para o julgamento das experiências. Assim, não há a substantivação de o Bem ou o Mal, mas a seleção constante dos encontros nas situações, sendo a natureza vista em movimento permanente, produzindo relações, misturas de corpos. A avaliação de um encontro como bom ou mau está ligada à possibilidade de expansão ou de decomposição que sofrem os corpos a partir das ligações estabelecidas. Os estóicos não fundam uma moral que dita o que deve ou não ser feito, como deve ser feito, mas uma ética que faculta o pensamento frente às experiências vividas por cada um. É ainda em Fuganti que se explicita a noção de uma ética da existência no estoicismo:

A ética é um saber das práticas ou das condutas que está colada à potência ou ao germe que se desenvolve em nós. Ela é uma dimensão individual que se instala entre a profundidade das misturas corpóreas e a superfície dos acontecimentos incorporais e que governa ou administra os afetos através dos encontros com os outros corpos. Um encontro, portanto, pode ser bom ou mau segundo nos fortaleça ou enfraqueça (FUGANTI, 1990, p. 52-53).

Os estóicos potencializam os corpos e priorizam as relações, retirando a virtude dos modelos transcendentais. Deste modo, criam uma microfísica e uma ética incompatíveis com o pensamento metafísico da representação e da moral, cujas bases remontam a Sócrates. Fuganti conclui que a moral que se afirma no dever e nas virtudes do homem de bem cede lugar a uma ética que põe em jogo o poder.

No século XVIII, Espinosa (1987) recoloca em cena a filosofia nômade dos pré-socráticos, que articula corpo e pensamento, produzindo modos de existência imanentes frente ao dualismo e determinismo causalista cartesiano e ao moralismo vigente dos teólogos. A imanência espinosista, segundo Deleuze (1968) se faz na distinção entre ética, produção da existência, e moral, relação da existência a valores transcendentes. Em sua ontologia, encontramos o corpo como potência de afetar e ser afetado. Quando um corpo age sobre outro, chamamos "afecção", ou seja, uma mistura de corpos em que se verifica uma ação recíproca onde os corpos recebem as relações características de cada um, produzindo transformações em seus estados anteriores. "Afecto" ${ }^{1}$ não é um sentimento do sujeito, mas o que vai desmanchar o sujeito, sendo, portanto, da ordem da não-representação. Neste sentido, a vida é química, um corpo é relação e suas possibilidades estão no limite de seu poder de ser afetado. 
Para Deleuze (1976a), o importante na obra espinosista é evidenciar a grande diferença entre a moral, fundada em valores superiores à vida, e a ética, que avalia as ações, tendo como base os modos de vida existentes que facultam a seleção dos encontros. Em Espinosa, também não existem os princípios universais do bem e do mal, mas o bom encontro que afeta, combina, modifica e aumenta a potência de agir de um corpo, e o mau encontro, que constitui uma mistura destrutiva porque redutora da potência de agir (ROLNIK, 1995). Na interpretação deleuzeana, Espinosa produz uma filosofia especulativa da univocidade do ser e, através do pensamento afirmativo, elabora uma filosofia prática da vida aliada à alegria. Os poderes opressores do Estado veiculam a esperança e o medo, o que Espinosa considera como paixões tristes que facultam a dominação e o controle dos homens, pois, afetados pela tristeza, tornam-se impotentes para produzir o devir. A esperança representa espera e não ação, assim como o medo leva ao imobilismo.

No século XIX, a filosofia da diferença é enfatizada na obra nietzscheana, afirma Deleuze (1976b) através do conceito de "eterno retorno". O mito fundador no platonismo traz na idéia eterna o padrão que determina o devir pelo estabelecimento das relações de identidade e semelhança. $\mathrm{O}$ caos é organizado no modelo perfeito e sua representação confere ordem ao mundo vivido. A radicalidade contida no movimento do eterno retorno constitui um antiplatonismo, onde o ser é múltiplo e se afirma no devir. O mundo verdadeiro não é mais estável, pois o eterno retorno é a criação do mundo afirmativo. O universo é uma composição de diversas forças e o fundamental é a análise de quais delas dominam. Para Nietzsche (1987), todo o conceito de verdade se modifica, porque um corpo se forma a partir de forças ativas (forças dominantes) e de forças reativas (forças dominadas). $\mathrm{O}$ pensamento não tem mais como função reproduzir a natureza, representando-a, mas sim produzi-la na expressão do mundo possível. O eterno retorno é o revir não ao idêntico, mas ao caos, à diferença, sendo que o revir é o ser, mas o ser que se afirma no devir. Assim, a doutrina de Nietzsche se constitui como máquina de guerra em favor de uma filosofia da diferença.

Nas análises de Machado, Deleuze associa o conceito de "eterno retorno" ao conceito de "vontade de potência", para melhor compreensão do princípio da diferença em Nietzsche:

Partindo da idéia de que aquilo que constitui a essência da força é a relação com outras forças ou que é na relação que a força adquire sua essência ou qualidade, Deleuze define um corpo como um fenômeno múltiplo, um composto de uma pluralidade de forças irredutíveis em luta, em que algumas forças são dominantes e outras dominadas (MACHADO, 1990, p. 87).

O princípio interno de determinação da diferença de quantidade das forças em luta e de determinação da qualidade das forças é, então, a vontade de potência. O autor conclui ainda que a vontade de potência não é a força, mas a diferença, o elemento diferencial que implica a relação entre as forças e 
a qualidade destas como ativas ou reativas. É justamente neste elemento diferencial que a afirmação se apresenta e se expressa como criação. Em Nietzsche (1987), a diferença não se vincula ao desvio e sim à criação, uma vez que não há modelos pré-constituídos.

Em Machado (1990) encontramos, então, que, para Platão e Aristóteles, a diferença só surge a partir da semelhança: na perspectiva platônica, só existe o mesmo e o outro enquanto cópia; no aristotelismo, a diferença é impensável, já que sempre é produzida como contradição. Platão quer "consertar" o mundo, expulsando as más cópias, os fantasmas; em Aristóteles, a questão se coloca como busca de conhecimento do mundo, sendo, portanto, de cunho epistemológico. Aristóteles não ousou; ele observou o que se passava, as configurações, e especializou a unidade. Em Nietzsche o abandono da perspectiva da representação se dá na capacidade de criar problemas, assim como na busca de saídas satisfatórias para estes. Na filosofia nietzscheana, não existe a coisa nem o eu em si: tudo é virtualidade interminável, dinamismos, forças em luta construindo o devir.

A ciência moderna construiu paradigmas que trabalham a diferença sob o crivo da avaliação quer de cunho quantitativo, quer qualitativo, nunca perdendo de vista os modelos referenciais. A diferença é desvio ou simulacro quando estabelecida a partir da identidade e semelhança a verdades pré-concebidas. $\mathrm{O}$ pensamento científico trabalha com a norma, excluindo o que se constitui como nuança. Em relação ao conhecimento, se queremos conhecer algo, a busca é dos múltiplos sentidos que isto já recebeu e não da verdade última que encerra, pois esta não existe. A compreensão das possibilidades relacionais, da luta de forças que se estabelecem na produção das formas é uma busca genealógica.

Em Naffah Neto (1992) também encontramos a abordagem nietzscheana para a interpretação da realidade. Segundo o autor, o real é produção contínua entre campos de força e é o campo de força vencedor que tenta impor seu sentido como universal. A visão é sempre parcial e está implicada com valores, com um momento singular. A verdade em Nietzsche é uma questão política. A história da humanidade é a história da moral, uma vez que o cristianismo espalhou a moral como forma de relação com a vida. Nietzsche estabelece o que para ele transcende a moral como o além-do-homem, o homem transmutado, que é o próprio homem como movimento e devir contínuos. O caos que retorna no eterno retorno é sempre a possibilidade de tudo se abrir, pois desmancha formas constituídas, liberando forças para novas criações.

Assim, criar alternativas para a vida, resgatar o movimento enquanto potência de transformação, implica na intensificação das experiências. Isso requer o redimensionamento do cotidiano em relação à lógica instituída, facultando a constituição de outros modos de subjetivação, o que não será conseguido mantendo-se intactas as noções de homem, de mundo e de futuro hegemônicas em nossa formação sócio-cultural. A sociedade e suas instituições se constituem como um sistema aberto, na medida em que as estruturas, os conceitos, as formas produzidas são reportadas a circunstâncias e não a essências. E é justamente a análise da 
circunstancialidade que pode contextualizar os modelos, evidenciando seu caráter histórico e singular, o que desconstroi o próprio estatuto de modelo. Nossas práticas estão referidas a razões e critérios naturalizados como universais, verdadeiros e científicos e, nesse sentido, são eternamente aplicáveis. Não se trata, portanto, de só escutar a realidade, mas de colocar em jogo os critérios e a lógica em que esta escuta se faz. Este é um caminho, não para negar os pressupostos teóricoconceituais, mas para utilizá-los a favor da afirmação da diferença. Eis uma possibilidade de desbloqueio do movimento, no qual é reinaugurada a luta incessante entre as forças pelo sentido da vida.

\section{Nota}

1 "Afecto" é utilizado para designar um estado do corpo onde a potência de agir é aumentada ou reduzida, favorecida ou bloqueada. Segundo Espinosa, afecto é uma noção confusa pela qual explicitamos um estado de paixão da alma, através do qual se afirma uma força de existir do corpo que envolve mais ou menos realidade que antes. "Um modo existente define-se por um certo poder de ser afectado" Deleuze, G. Espinoza e os signos. Porto, Rés editora limitada, 1976, p.51.

\section{REFERÊNCIAS}

DELEUZE, G. Diferença e repetição. Rio de Janeiro: Graal, 1988. . Espinoza e os signos. Porto: Rés, 1976a. . Lógica do sentido. São Paulo: Perspectiva, 1974. . Nietzsche e a filosofia. Rio de Janeiro: Rio, $1976 \mathrm{~b}$. . Spinoza: Philosophie pratique. Paris: Minuit, 1968.

ESPINOZA, B. Ética. São Paulo: Nova Cultural, 1987.

FUGANTI, L. A. Saúde, desejo e pensamento. Saúde e Loucura, São Paulo, v.2, p. 19-82, 1990.

GUATTARI, F. Micropolítica. In: ROLNIK, S. Micropolítica: cartografias do desejo. Petrópolis: Vozes, 1986.

GUSDORF, G. Mythe et métaphysique. Paris: Flammarion, 1984.

KASTRUP, V. A invenção de si e do mundo: uma introdução do tempo e do coletivo no estudo da cognição. Campinas: Papirus, 1999.

MACHADO, R. Deleuze e a filosofia. Rio de Janeiro: Graal, 1990.

MENGUE, P. Gilles Deleuze ou le système du multiple. Paris: Kimé, 1994.

NAFFAH NETO, A. O inconsciente como potência subversiva. São Paulo: Escuta, 1992.

NIETZSCHE, F. Obras incompletas. São Paulo: Nova Cultura, 1987.

ORLANDI, L. B. L. Simulacro na filosofia de Deleuze. Revista 34 letras, Rio de Janeiro, v. 5, n. 6, p. 208-222, 1989. 
ROLNIK, S. À sombra da cidadania: alteridade, homem da ética e reivindicação de democracia. In: MAGALHÃES, M. C. R. (Org.). Na sombra da cidade. São Paulo: Escuta, 1995.

ULPIANO, C. A Estética Deleuziana. Oficina Três Rios, PUC/SP (22 e 24/11/ 1993). Transcrição das oficinas realizadas na PUC/SP para o curso de PósGraduação em Psicologia Clínica, p. 6.

ZOURABICHVILI, F. Deleuze: une philosophie de l'événement. Paris: PUF, 1994.

Recebido em: março/ 2005. Aceito em: junho/ 2006. 